\title{
Pre-existing psychological depression confers increased risk of adverse cardiovascular outcomes following cardiac surgery: A systematic review and meta-analysis
}

\author{
Lauren B. Flaherty, MA, ${ }^{\mathrm{a}}$ Taylor Wood, BS, ${ }^{\mathrm{b}}$ Allen Cheng, MD, ${ }^{\mathrm{c}}$ and Abdur R. Khan, $\mathrm{MD}^{\mathrm{b}}$
}

\footnotetext{
From the ${ }^{\mathrm{a}}$ Department of Psychological and Brain Sciences, University of Louisville School of Arts and Sciences, and the ${ }^{\mathrm{b}}$ Division of Cardiovascular Medicine, University of Louisville School of Medicine, Louisville, Ky; and the ${ }^{\mathrm{c}}$ Division of Cardiothoracic Surgery, Washington University School of Medicine, St Louis, Mo.

Received for publication Feb 25, 2017; revisions received June 2, 2017; accepted for publication June 28, 2017; available ahead of print Aug 14, 2017

Address for reprints: Abdur R. Khan, MD, Division of Cardiovascular Medicine, University of Louisville School of Medicine, Rudd Heart \& Lung Suite 600, 201 Abraham Flexner Way, Louisville, KY 40202 (E-mail: abdur. khan@louisville.edu).

J Thorac Cardiovasc Surg 2017;154:1578-86

$0022-5223 / \$ 36.00$

Copyright $\odot 2017$ by The American Association for Thoracic Surgery

http://dx.doi.org/10.1016/j.jtcvs.2017.06.052
}

The prevalence of major depression is estimated to be around $17 \%$ in all age groups and $11 \%$ in individuals aged 60 years or older, the age group that more commonly presents with cardiovascular disease $(\mathrm{CVD}){ }^{1}{ }^{1}$ The prevalence of psychological depression is higher in patients with CVD and is reported to be around $20 \%$ to $40 \%{ }^{2}$ Whether depression has prognostic influence in patients with CVD is no longer a matter of debate. In fact, depression has been associated with an increased risk both for the development and progression of $\mathrm{CVD},{ }^{2}$ particularly in the case of coronary artery disease (CAD) ${ }^{3-6}$ In adult patients who develop severe $\mathrm{CAD}$ requiring surgical revascularization by way of coronary artery bypass grafting (CABG), the coexistence of psychological depression apparently confers an increased risk for postoperative morbidity (ie, major adverse cardiovascular events, including cardiac death, myocardial infarction, cardiac arrest, and urgent revascularization) and rehospitalization as well as decreased long-term survival. ${ }^{7-14}$

An ongoing challenge to clinicians is the accurate assessment of depression in this cohort. Indeed, there are conflicting reports regarding the modality used to assess depression and its association with clinical outcomes. ${ }^{3-6}$ Recognition of pre-existing depression in patients undergoing $\mathrm{CABG}$ can be obscured not only by symptoms experienced from CAD, but also the physical stress of the surgery itself. ${ }^{13}$ Consequently, no real consensus exists regarding clinical outcome risk as it relates to the diagnosis of depression in patients undergoing CABG.

We performed a systematic review and meta-analysis to summarize the existing evidence regarding associations between pre-existing depression with cardiac-related morbidity and all-cause mortality in patients who undergo CABG. Additionally, we chose to investigate whether the diagnostic modality chosen to define depression influences the relationship between depression and clinical outcomes (Video 1).

\section{METHODS}

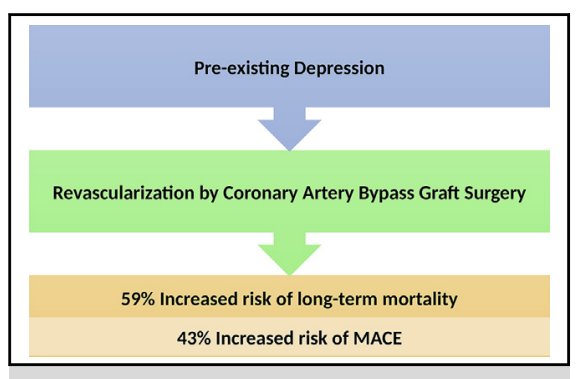

Pre-existing depression confers increased risk for both long-term mortality and major adverse cardiovascular events after coronary artery bypass grafting

Central Message
In patients undergoing coronary artery bypass
grafting, pre-existing depression was signifi-
cantly associated with increased risk for both
long-term mortality and major adverse cardio-
vascular events.

Perspective

Depressed patients undergoing coronary artery bypass grafting experience worse clinical outcomes. However, data are limited in this patient population. Existing evidence suggests that pre-existing depression is associated with morbidity and mortality in patients who undergo coronary artery bypass grafting. Whether pre-existing depression truly influences clinical outcomes postoperatively remains unresolved.

See Editorial Commentary page 1587.

\section{Data Sources and Search Strategy}

The literature search was carried out under the guidance of an experienced librarian. The search was carried out in several databases: PubMed, Embase, Cochrane Central Register of Controlled Trials, PsycINFO, and Web of Science from inception through November 8, 2016. The following medical subject headings, Embase subject headings, and key word search terms were used in combination: depression, depressive disorder, coronary artery bypass graft surgery, coronary artery bypass grafting, CABG, morbidity, mortality, clinical outcomes, and

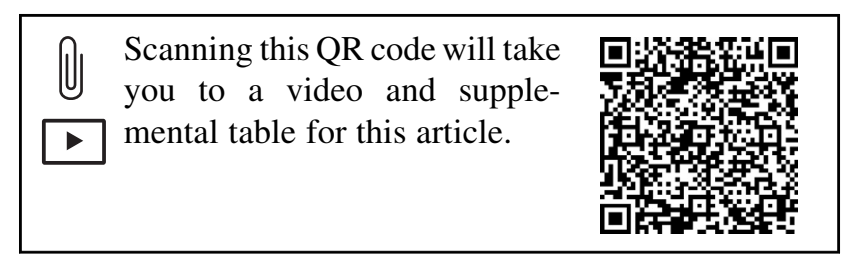


survival. The search accounted for plurals and variations in spelling with the use of appropriate wildcards. To identify further articles, we hand-searched related citations in review articles and commentaries. Published abstracts or unpublished data were not included because reports indicate discrepancies between published and unpublished data. ${ }^{15,16}$ All results were downloaded into EndNote (Clarivate Analytics, Philadelphia, $\mathrm{Pa}$ ) and duplicate citations were identified and removed.

\section{Study Selection}

The eligibility of studies was assessed by 2 investigators (T.W. and L.B.F.) independent of each other. Included studies were those that compared clinical outcomes in patients with or without depression who underwent myocardial revascularization with CABG. There was no restriction of study design, language, or number of participants. In the case of $>1$ study from the same population, we included the study that had more number of patients or a longer follow-up period. Studies were excluded if they reported outcomes from the same patient population, reported no clinical outcomes, or reported outcomes other than those relevant to our analysis.

\section{Data Extraction}

Two reviewers (L.B.F. and A.C.) extracted data from the included studies independently from each other. The data were extracted into a predefined spreadsheet that included details about the study characteristics, setting (in-hospital or general population), study design, patient characteristics, details of the surgical procedure, and relevant outcomes. Because the modality for diagnosing depression differed amongst the included studies, the diagnosis of depression was accepted in our analysis as reported by the individual studies. The relevant outcomes measured in our analysis were all-cause mortality or a combined end point of cardiac mortality and morbidity in patients with depression who underwent CABG. The definition of morbidity varied in the included studies but included angina, myocardial infarction, stroke, rehospitalization, infection, or a repeat procedure in almost all of the studies. There was no a priori definition of the time of assessment of mortality or morbidity and definitions were accepted as reported in the included studies. Long-term mortality was considered after 12 months because early outcomes may be influenced by the associated surgical risk.

\section{Data Synthesis and Statistical Analysis}

Continuous data were reported either as mean \pm standard deviation or median (interquartile range). The primary effect measure included in our analysis was hazard ratio (HR), as reported in the studies. One study reported adjusted odds ratio (OR), which was used to calculate relative risk because both measures of association are known to approximate each other when the incidence of events in the control population are low. Both relative risk and HR were assumed to evaluate the same association and were pooled together. The relevant outcomes in our analysis were pooled with only adjusted effect estimates by the generic inverse variance method using a random-effects model based on the associated heterogeneity encountered. The $I^{2}$ statistic was used to assess heterogeneity among studies. ${ }^{17}$ Publication bias was not assessed because of a limited number of studies. Unadjusted effect estimates were not included in our analysis to decrease bias. Sensitivity analysis was done to investigate the robustness of the effect estimate by 1-study removal analysis. Subgroup analysis was done to evaluate any difference in outcomes based on the assessment or definition of depression (objective assessment by questionnaires compared with diagnosis from administrative, pharmacy, or hospital databases).

\section{Quality Assessment}

Two reviewers (L.B.F. and A.R.K.) independently assessed the methodologic quality of the selected studies using the NewcastleOttawa Scale. This scale involves evaluation of observational studies

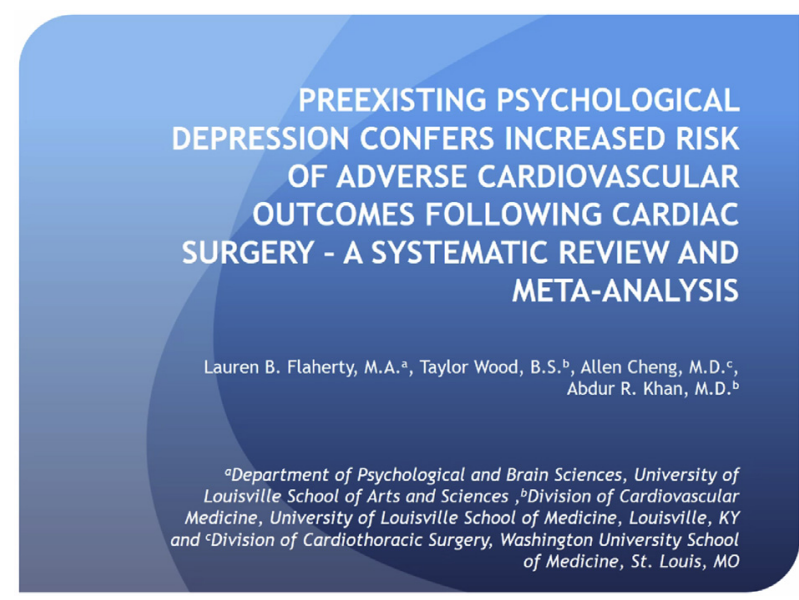

VIDEO 1. Summary of our findings and their importance. Video available at: http://www.jtcvsonline.org/article/S0022-5223(17)31371-5/fulltext.

based on 3 areas: selection of the study groups, comparability among groups, and the assessment of outcome among the groups. ${ }^{18}$ The scale assigns a maximum of 4 points for selection, 2 points for comparability, and 3 points for exposure/outcome assessment. Studies with $>7$ points were considered high quality and studies with $<5$ points were considered low quality. Any disagreements between reviewers in study inclusion, data extraction, and quality assessment were resolved by consensus. All analyses were conducted using the statistical software Review Manager version 5.2 (Cochrane Community, London, United Kingdom). Our systematic review was carried out in accordance with the Preferred Reporting Items for Systematic Reviews and Metaanalyses and meta-analysis of observational studies in epidemiology guidelines. ${ }^{19,20}$

\section{RESULTS}

The literature search identified 1388 publications, out of which 10 studies were eligible for our analysis ${ }^{14,21-30}$ (Figure 1). Connerney and colleagues ${ }^{21}$ reported cardiac morbidity at 1 year and mortality at 10 years ${ }^{22}$ in 2 different studies, both of which were included in our analysis. Included studies were observational, with data extracted either from in-patient hospital records or administrative and pharmacy databases. Studies reported outcomes in a cohort of patients with depression and reported adjusted outcomes in all studies except 2 , which reported unadjusted outcomes. Blumenthal and colleagues ${ }^{23}$ reported outcomes for both major and minor depression separately, which were combined for our analysis. Two studies reported unadjusted outcomes and were not included in our analysis outcomes. ${ }^{9,31}$ All of the observational studies had good methodologic quality, as assessed by the NewcastleOttawa Scale with a score $\geq 7$. Table 1 summarizes the characteristics of the included studies. Table 2 highlights the characteristics of the patient populations in these studies. A total of 10 studies comprising 152,491 participants (ranging from 119 to 62,656 in individual studies), the largest population studied to date, were included in the analysis. The included studies were conducted in the United States, Australia, and Sweden. 


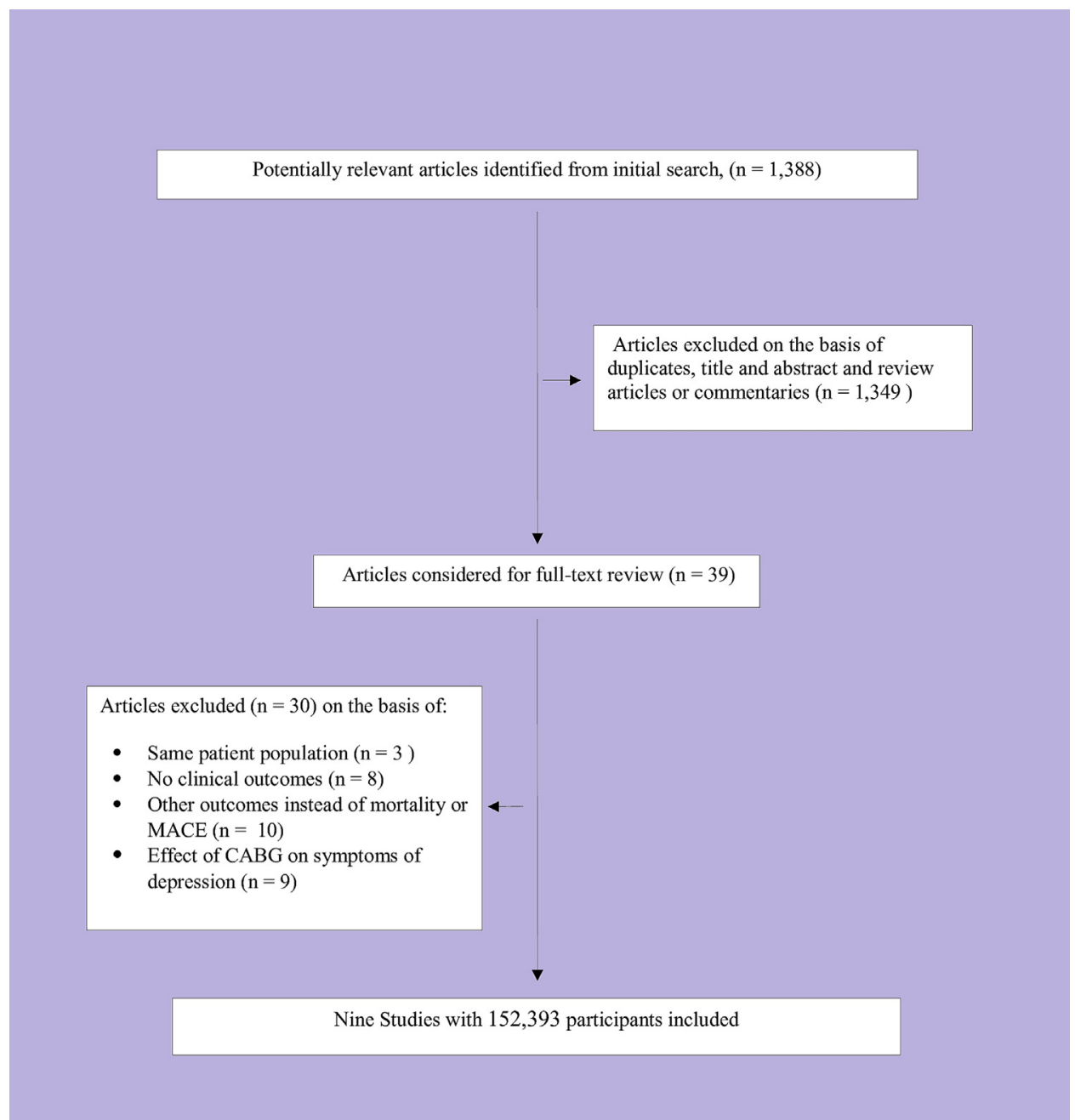

FIGURE 1. Flowchart of eligible studies. $M A C E$, Major adverse cardiovascular events; $C A B G$, coronary artery bypass graft.

The patients included in the studies were predominantly men with a mean age of approximately 61 years. Reported associated comorbidities and other confounders were adjusted for the multivariate analysis or were propensity matched for the analysis (Table E1). The prevalence of depression was $13.6 \%(20,673$ out of 152,491$)$ before surgery. The diagnosis and severity of depression was evaluated in the studies either by questionnaires or by the administrative databases. There were different questionnaires used to assess depression: the Depression Anxiety Stress Scale was used in 1 study, ${ }^{26}$ Center for Epidemiological Studies-Depression in 1 study, ${ }^{23}$ Beck's Depression Inventory in 2 studies, ${ }^{14,22}$ and by the Diagnostic Interview Schedule in 1 study. ${ }^{22}$ In the administrative databases, depression was coded per the guidelines from International Classification of Diseases code (9th and 10th revisions) $)^{27,29,30}$ or by the use of antidepressants $^{28}$ (Tables 2 and 3).

All patients included in the analysis underwent CABG; either isolated CABG or with concomitant valve surgery.

\section{All-Cause Mortality}

All the studies provided outcomes for all-cause mortality in patients with depression who underwent CABG. All studies reported mortality beyond 6 months except 1 study, ${ }^{27}$ in which in-hospital mortality was evaluated. Nine studies reported time-to-event outcomes as HR, and 1 study reported adjusted OR.

Our meta-analysis definitively showed an increased risk of mortality associated with moderate heterogeneity (HR, 1.42; 95\% confidence interval [CI], 1.26-1.60; $\left.P<.00001 ; I^{2}=37 \%\right)$ in patients with depression who underwent CABG (Figure 2). Moreover, there was little variability in the pooled results, with 1-study removal analysis further suggesting the robustness of the results (HR, 1.35-1.46; 95\% CI, 1.21-1.29 to 1.51-1.68). Also, removal of the study that reported adjusted OR did not change the effect estimate (OR, 1.46; 95\% CI, 1.27-1.68; $P<.00001)$. There was little difference in mortality risk based on the diagnostic modality used to assess depression; that is, questionnaire-based method (HR, 1.63; 95\% CI, 
TABLE 1. Characteristics of included studies

\begin{tabular}{|c|c|c|c|c|c|c|c|}
\hline Study; period & Center & Study design & $\begin{array}{l}\text { Inclusion criteria }(\mathrm{I}) \text { and } \\
\text { exclusion criteria }(\mathrm{E})\end{array}$ & $\begin{array}{c}\text { Analytical } \\
\text { method }\end{array}$ & Outcome & Follow-up & NOS \\
\hline $\begin{array}{l}\text { Connerney, } 2001 \\
\text { and 2010; } \\
\text { 1997-2008 }\end{array}$ & $\begin{array}{l}\text { Single, } \\
\quad \text { United States }\end{array}$ & $\begin{array}{l}\text { Observational } \\
\text { cohort study }\end{array}$ & $\begin{array}{l}\text { (I) CABG recipients } \\
\text { (E) Too severely ill, poor } \\
\text { command of English } \\
\text { language }\end{array}$ & $\begin{array}{l}\text { Cox proportional- } \\
\text { hazards }\end{array}$ & $\begin{array}{l}\text { All-cause mortality, cardiac } \\
\text { mortality, readmission } \\
\text { due to angina, MI, HF, } \\
\text { repeat procedure }\end{array}$ & $\begin{array}{l}1 \mathrm{y} ; \\
\quad \text { median } \\
9.3 \mathrm{y}\end{array}$ & 9 \\
\hline $\begin{array}{l}\text { Blumenthal, 2003; } \\
\text { 1989-2001 }\end{array}$ & $\begin{array}{l}\text { Single, } \\
\quad \text { United States }\end{array}$ & $\begin{array}{l}\text { Observational } \\
\text { cohort }\end{array}$ & $\begin{array}{l}\text { (I) CABG recipients } \\
\text { (E) Concomitant thoracic } \\
\text { surgeries, serious medical } \\
\text { comorbidities, substantial } \\
\text { cognitive difficulties, } \\
\text { psychiatric disorder besides } \\
\text { depression }\end{array}$ & Cox regression & All-cause mortality & $12 \mathrm{y}$ & 9 \\
\hline Oxlad, 2006 & 2, Australia & $\begin{array}{l}\text { Observational } \\
\text { cohort study }\end{array}$ & $\begin{array}{l}\text { (I) } \mathrm{CABG} \pm \text { valve surgery } \\
\text { recipients } \\
\text { (E) Emergency surgery }\end{array}$ & $\begin{array}{l}\text { Cox proportional- } \\
\text { hazards }\end{array}$ & $\begin{array}{l}\text { Cardiac-related } \\
\text { hospital } \\
\text { readmission }\end{array}$ & $6 \mathrm{mo}$ & 7 \\
\hline $\begin{array}{r}\text { Xiong, 2006; } \\
1999-2003\end{array}$ & $\begin{array}{l}\text { Single, } \\
\quad \text { United States }\end{array}$ & $\begin{array}{l}\text { Observational } \\
\text { cohort study }\end{array}$ & $\begin{array}{l}\text { (I) CABG recipients } \\
\text { (E) Combined } C A B G \text { and } \\
\text { valve surgery }\end{array}$ & $\begin{array}{l}\text { Cox proportional } \\
\text { hazards }\end{array}$ & $\begin{array}{l}\text { All-cause mortality, } \\
\text { rehospitalization, } \\
\text { combined end } \\
\text { point of mortality } \\
\text { or rehospitalization }\end{array}$ & $\begin{array}{c}\text { Median } \\
3 \mathrm{y}\end{array}$ & 9 \\
\hline $\begin{array}{l}\text { Tully, 2008; } \\
\text { 1996-2006 }\end{array}$ & $\begin{array}{l}\text { Single, } \\
\quad \text { Australia }\end{array}$ & $\begin{array}{l}\text { Observational } \\
\text { longitudinal } \\
\text { study }\end{array}$ & $\begin{array}{l}\text { (I) CABG, age > } 18 \text { y } \\
\text { (E) Reading, writing, or } \\
\text { vision difficulties, } \\
\text { emergency surgery, } \\
\text { dementia, psychotic } \\
\text { personality, or } \\
\text { developmental disorder }\end{array}$ & $\begin{array}{l}\text { Multivariable } \\
\text { proportional } \\
\text { hazards }\end{array}$ & All-cause mortality & $\begin{array}{c}\text { Median } \\
5 \mathrm{y}\end{array}$ & 9 \\
\hline Dao, 2010; 2006 & $\begin{array}{l}\text { 1000, } \\
\text { United States }\end{array}$ & $\begin{array}{l}\text { Retrospective } \\
\text { cohort }\end{array}$ & $\begin{array}{l}\text { (I) CABG recipients } \\
\text { (E) NR }\end{array}$ & $\begin{array}{l}\text { Hierarchic logistic } \\
\text { regression }\end{array}$ & In-hospital mortality & In-hospital & 8 \\
\hline $\begin{array}{l}\text { Tully, 2011; } \\
\quad \text { 1999-2003 }\end{array}$ & $\begin{array}{l}\text { Single, } \\
\text { Australia }\end{array}$ & $\begin{array}{l}\text { Observational } \\
\text { longitudinal } \\
\text { study }\end{array}$ & $\begin{array}{l}\text { (I) CABG, age > } 18 \text { y } \\
\text { (E) Reading, writing, or } \\
\text { vision difficulties, } \\
\text { emergency surgery, } \\
\text { dementia, psychotic } \\
\text { personality, or } \\
\text { developmental disorder }\end{array}$ & $\begin{array}{l}\text { Log rank test, } \\
\text { survival analysis }\end{array}$ & $\begin{array}{l}\text { Cardiac morbidity and } \\
\text { mortality }\end{array}$ & $\begin{array}{r}\text { Median } \\
4.9 \mathrm{y}\end{array}$ & 9 \\
\hline $\begin{array}{l}\text { Tully, 2012; } \\
\text { 1996-2008 }\end{array}$ & $\begin{array}{l}\text { Single, } \\
\text { Australia }\end{array}$ & $\begin{array}{l}\text { Observational } \\
\text { cohort study }\end{array}$ & $\begin{array}{l}\text { (I) CABG recipients } \\
\text { (E) Use of psychotropic } \\
\text { medications other than } \\
\text { SSRIs/SNRIs }\end{array}$ & $\begin{array}{l}\text { Propensity score, } \\
\text { Cox proportional } \\
\text { hazards }\end{array}$ & $\begin{array}{l}\text { Mortality ( }<30 \mathrm{~d} \text { and long-term), } \\
\text { in-hospital morbidity, bleeding, } \\
\text { reoperation, renal dysfunction, } \\
\text { ventilation }>24 \mathrm{~h} \text {, sterna } \\
\text { wound infection, MI events, } \\
\text { stroke }\end{array}$ & $\begin{array}{r}\text { Median } \\
4.7 \mathrm{y}\end{array}$ & 9 \\
\hline $\begin{array}{c}\text { Stenman, 2014; } \\
\text { 1997-2008 }\end{array}$ & $\begin{array}{l}\text { Registry, } \\
\text { Sweden }\end{array}$ & $\begin{array}{l}\text { Retrospective } \\
\text { cohort study, } \\
\text { SWEDEHEART } \\
\text { registry }\end{array}$ & $\begin{array}{l}\text { (I) } \text { CABG recipients } \\
\text { (E) Previous cardiac } \\
\text { surgery, concomitant } \\
\text { procedures in addition } \\
\text { to CABG, emergency } \\
\text { surgery }\end{array}$ & $\begin{array}{l}\text { Cox proportional } \\
\text { hazards }\end{array}$ & $\begin{array}{l}\text { All-cause mortality; combined } \\
\text { end point of all-cause } \\
\text { mortality, MI, rehospitalization, } \\
\text { heart failure, or stroke }\end{array}$ & $\begin{array}{l}\text { Mean } \\
7.5 \mathrm{y}\end{array}$ & 9 \\
\hline $\begin{array}{l}\text { Stenman, 2015; } \\
\text { 2006-2013 }\end{array}$ & $\begin{array}{l}\text { Registry, } \\
\text { Sweden }\end{array}$ & $\begin{array}{l}\text { Retrospective } \\
\text { cohort, } \\
\text { SWEDEHEART } \\
\text { registry }\end{array}$ & $\begin{array}{l}\text { (I) CABG recipients } \\
\text { (E) Previous cardiac } \\
\text { surgery, concomitant } \\
\text { procedures in addition } \\
\text { to CABG, emergency } \\
\text { surgery }\end{array}$ & $\begin{array}{l}\text { Cox proportional } \\
\text { hazards }\end{array}$ & All-cause mortality & $\begin{array}{l}\text { Mean } \\
4.1 \mathrm{y}\end{array}$ & 9 \\
\hline
\end{tabular}

NOS, Newcastle Ottawa Scale; $C A B G$, coronary artery bypass grafting; $M I$, myocardial infarction: $H F$, heart failure; $N R$, not reported; $S S R I$, selective serotonin reuptake inhibitor; SNRI, serotonin norepinephrine reuptake inhibitor; SWEDEHEART, Swedish Web system for Enhancement and Development of Evidence-based care in Heart disease Evaluated According to Recommended Therapies. 
TABLE 2. Baseline characteristics of the included patients

\begin{tabular}{|c|c|c|c|c|c|c|c|c|c|c|}
\hline Study & Group & $\mathbf{N}$ & $\begin{array}{c}\text { Mean } \\
\text { age }(y)\end{array}$ & Male (\%) & $\begin{array}{c}\text { Smoking } \\
(\%)\end{array}$ & $\begin{array}{l}\text { DM } \\
(\%)\end{array}$ & $\begin{array}{r}\text { HTN } \\
(\%)\end{array}$ & HPL (\%) & Prior MI (\%) & $\mathrm{EF}(\%)$ \\
\hline \multirow{2}{*}{$\begin{array}{l}\text { Connerny, } 2001 \\
\text { and } 2010\end{array}$} & Depressed & 63 & $63.1 \pm 10.2$ & 67 & 28 & 36 & 76 & 57 & 52 & $48 \pm 13$ \\
\hline & Nondepressed & 246 & & & & & & & & \\
\hline \multirow[t]{3}{*}{ Blumenthal, 2003} & Mild depression & 213 & $61 \pm 10.7$ & 64 & 72 & 24 & NR & NR & 53 & $52 \pm 11.7$ \\
\hline & $\begin{array}{l}\text { Moderate to severe } \\
\text { depression }\end{array}$ & 97 & $57 \pm 9.4$ & 58 & 66 & 26 & NR & NR & 51 & $55 \pm 11$ \\
\hline & Nondepressed & 507 & $62 \pm 10$ & 80 & 67 & 23 & NR & NR & 50 & $54 \pm 2.2$ \\
\hline \multirow[t]{2}{*}{ Oxlad, 2006} & Depressed & 17 & $63.3 \pm 10.2$ & NR & NR & NR & NR & NR & NR & NR \\
\hline & Nondepressed & 102 & & & & & & & & \\
\hline \multirow[t]{2}{*}{ Xiong, 2006} & Depressed & 246 & 63 & 56.1 & 28.9 & 46.3 & 80.5 & 20.3 & 38.2 & NR \\
\hline & Nondepressed & 4548 & 64 & 70.9 & 32.2 & 34.2 & 69.5 & 15.0 & 40.4 & NR \\
\hline \multirow[t]{2}{*}{ Tully, 2008} & Depressed & 89 & NR & 80 & NR & 19 & 56.4 & NR & 7.0 & NR \\
\hline & Nondepressed & 351 & & & & & & & & \\
\hline \multirow[t]{2}{*}{ Dao, 2010} & Depressed & 16,215 & $66 \pm 10.87$ & 71.3 & NR & 30.2 & NR & NR & 34.2 & NR \\
\hline & Nondepressed & 46,441 & & & & & & & & \\
\hline Tully, 2011 & Depressed & 226 & $63 \pm 9.7$ & 83 & 69.9 & 20.8 & 61.5 & 69 & 8.4 & NR \\
\hline \multirow[t]{2}{*}{ Tully, 2012} & Depressed & 105 & NR & 54.3 & 73.3 & 36.2 & 74.3 & NR & 90.5 & NR \\
\hline & Nondepressed & 4031 & NR & 73.2 & 69.3 & 27.1 & 60.9 & NR & 85.1 & NR \\
\hline \multirow[t]{2}{*}{ Stenman, 2014} & Depressed & 324 & $66.1 \pm 9.8$ & 58 & 24 & 41 & 56 & 62 & 52 & NR \\
\hline & Nondepressed & 55,740 & $66.7 \pm 9.3$ & 78 & 19 & 22 & 56 & 58 & 42 & NR \\
\hline \multirow[t]{2}{*}{ Stenman, 2015} & Depressed & 3078 & $65.9 \pm 9.7$ & 67.2 & NR & 32.6 & 50.7 & 28.9 & 58.9 & NR \\
\hline & Nondepressed & 19,852 & $67.7 \pm 9.1$ & 82.1 & NR & 26.2 & 45.1 & 25 & 55.9 & NR \\
\hline
\end{tabular}

$D M$, Diabetes mellitus; $H T N$, hypertension; $H P L$, hyperlipidemia; $M I$, myocardial infarction; $E F$, ejection fraction; $N R$, not reported.

$\left.1.13-2.35 ; \quad P<.01 ; \quad I^{2}=44 \%\right)$ compared with administrative record review method (HR, 1.39; 95\% CI, $1.21-1.61 ; P<.00001 ; I^{2}=51 \%$ ) (Figure 3). However, depression diagnosed using a questionnaire-based assessment was associated with a greater $(24 \%)$ risk for long-term mortality.

\section{Composite End Point: Cardiac Mortality and Morbidity}

Six studies reported the association of depression on a composite end point of cardiac mortality and morbidity. ${ }^{14,21,24,25,28,29}$ As mentioned, there was minor variability in the definition of morbidity in the studies;

TABLE 3. Clinical outcomes in patients with depression after coronary artery bypass grafting (CABG)

\begin{tabular}{|c|c|c|c|c|}
\hline \multirow[b]{2}{*}{ Study, y } & \multicolumn{2}{|c|}{ Depression } & \multirow[b]{2}{*}{ All-cause mortality* } & \multirow[b]{2}{*}{ Composite end point } \\
\hline & Diagnosis/severity & Prevalence & & \\
\hline Connerney, 2001 and 2010 & BDI & 20.4 & HR, 1.19 (0.78-1.82) & RR, 2.31 (1.17-4.56) \\
\hline Blumenthal, 2003 & CES-D $>16$ & 38 & HR, $1.48(1.06-2.07) \dagger$ & NR \\
\hline Oxlad, 2006 & DASS & 14.5 & NR & $\mathrm{RR}, 5.15(1.45-18.28)$ \\
\hline Xiong, 2006 & Pharmacy Records & 5.1 & HR, 1.61 (1.17-2.21) & HR, $1.46(1.26-1.70)$ \\
\hline Tully, 2008 & DASS-D $\geq 10$ & 20 & HR, 1.61 (0.91-2.85) & NR \\
\hline Dao, 2010 & ICD code & 25.9 & RR, 1.24 (1.02-1.50) & NR \\
\hline Tully, 2011 & BDI-II & 20.1 & NR & HR, $1.36(1.02-1.82)$ \\
\hline Tully, 2012 & SSRI/SNRI use & 2.5 & RR, $1.60(0.59-4.34)$ & RR, 1.47 (0.95-2.27) \\
\hline Stenman, 2014 & ICD code & 0.6 & HR, 1.65 (1.37-1.99) & HR, 1.61 (1.38-1.89) \\
\hline Stenman, 2015 & National Patient Register & 13.4 & HR, 1.25 (1.11-1.41) & NR \\
\hline
\end{tabular}

BDI, Beck's Depression Inventory; $H R$, hazard ratio; $R R$, relative risk; $C E S-D$, Center for Epidemiological Studies-Depression; NR, not reported; DASS, Depression Anxiety Stress Scale; ICD, International Classification of Diseases; SSRI, selective serotonin reuptake inhibitor; SNRI, serotonin norepinephrine reuptake inhibitor. *Adjusted effect estimate if not specified. †Combined HR of mild and moderate-to-severe depression. $\ddagger$ Adjusted only for cardiopulmonary bypass time. 


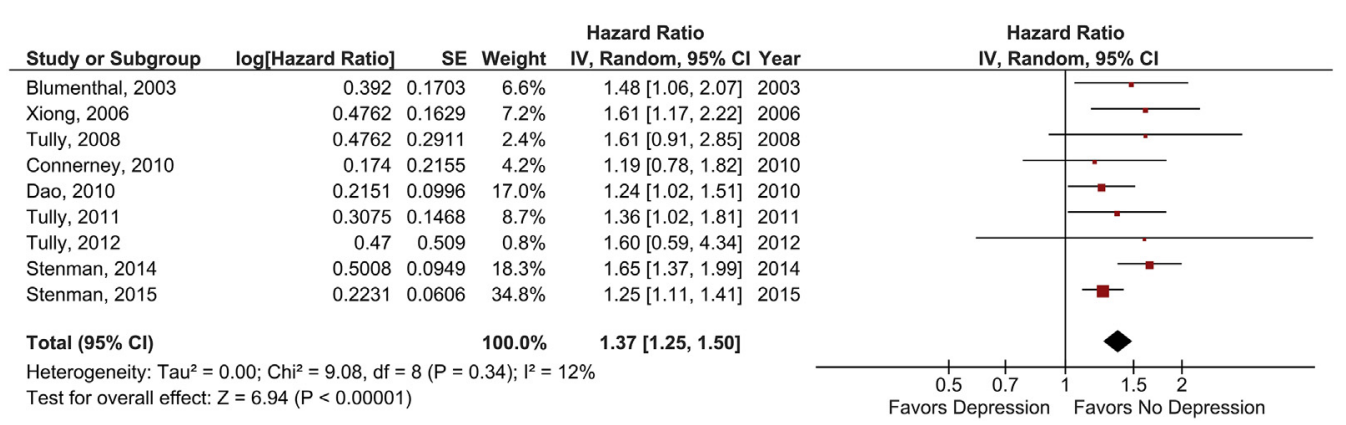

FIGURE 2. Forest plot comparing mortality in patients with depression who underwent coronary artery bypass grafting (CABG). Squares represent the hazard ratio of mortality in patients with depression who underwent CABG in the individual studies. Horizontal lines represent the $95 \%$ confidence intervals $(C I s)$ of the hazard ratio. The size of the square reflects the weight that the corresponding study exerts in the meta-analysis. The diamond represents the pooled hazard ratio showing an increased risk of mortality with depression in patients who undergo myocardial revascularization with CABG. SE, Standard error; $I V$, inverse variance.

however, the vast majority included angina, myocardial infarction, stroke, heart failure, arrhythmia, and rehospitalization. All studies reported outcomes adjusted for multiple variables save 1 study, ${ }^{24}$ in which the only adjustment was for the cardiopulmonary bypass time.

Our analysis revealed an increased risk for cardiac mortality and morbidity associated with depression (HR, 1.57; 95\% CI, 1.39-1.77; $P<.00001$ ) (Figure 4) with mild heterogeneity $\left(I^{2}=12 \% ; P=.34\right)$. Investigation of the heterogeneity showed all the heterogeneity was due to the study by Oxlad and colleagues, ${ }^{24}$ who adjusted the outcome for only 1 variable. Removal of the study did not change either the size or direction of the pooled effect estimate, which suggested an increased risk of cardiac mortality and morbidity associated with depression (HR, 1.55; 95\% CI, 1.40-1.71; $\left.I^{2}=0 \%\right)$.

\section{DISCUSSION}

This meta-analysis of patients with pre-existing depression who underwent CABG is the largest cohort studied to date and the most comprehensive study of its kind. Here, we report the following salient findings: we definitely established an association between pre-existing psychological depression and decreased long-term survival; our meta-analysis demonstrates that when additional relevant cardiac outcomes, including, specifically, cardiac mortality, and cardiac morbidity (as part of a combined clinical end point to include major adverse clinical events and rehospitalization), are considered, the negative association between depression and mortality persists; and the risk of mortality was not significantly influenced by the modality used to diagnose depression in the cohort.

Data from a very recent meta-analysis suggested an association between depression and decreased long-term

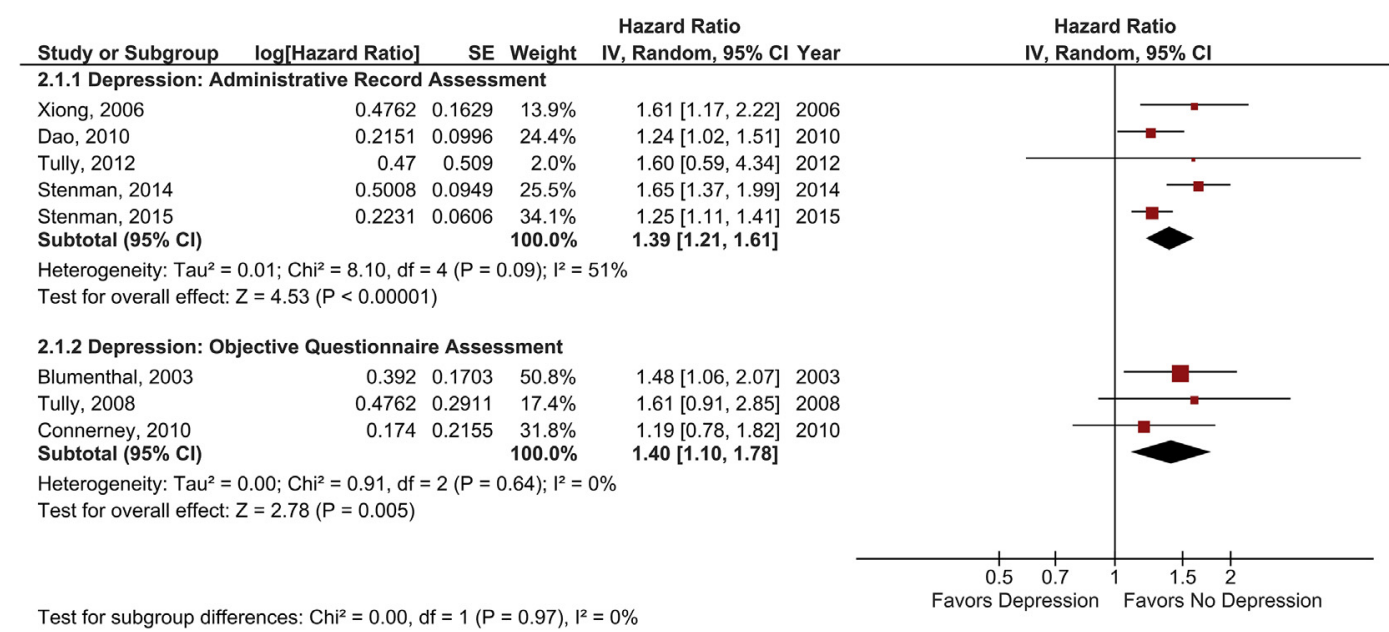

FIGURE 3. Forest plot comparing mortality in patients with depression who underwent coronary artery bypass grafting (CABG). Subgroups are based on the assessment and diagnosis of depression (upper panel shows administrative records, whereas lower panel shows questionnaire-based assessment). Squares represent the hazard ratio of mortality in patients with depression who underwent CABG in the individual studies. Horizontal lines represent the $95 \%$ confidence intervals $(C I s)$ of the hazard ratio. The size of the square reflects the weight that the corresponding study exerts in the meta-analysis. The diamond represents the pooled hazard ratio showing an increased risk of mortality with depression in patients who undergo myocardial revascularization with CABG. $S E$, Standard error; $I V$, inverse variance. 


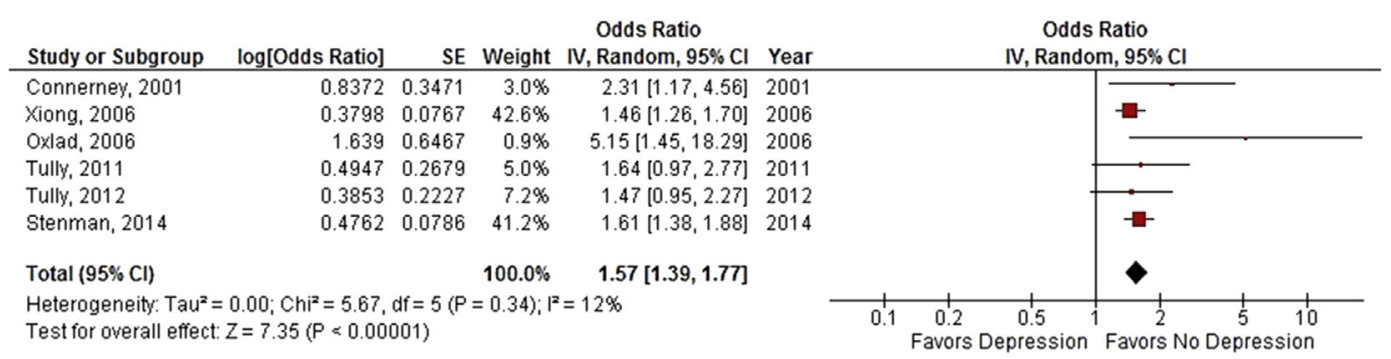

FIGURE 4. Forest plot comparing the composite end point of cardiac mortality and morbidity in patients with depression who underwent coronary artery bypass grafting (CABG). Squares represent the odds ratio of combined end point in patients with depression who underwent CABG in the individual studies. Horizontal lines represent the $95 \%$ confidence intervals (CIs) of the odds ratio. The size of the square reflects the weight that the corresponding study exerts in the meta-analysis. The diamond represents the pooled odds ratio showing an increased risk of composite end point with depression in patients who undergo myocardial revascularization with $\mathrm{CABG}$. $S E$, Standard error; $I V$, inverse variance.

survival following $\mathrm{CABG} .^{7}$ However, that study failed to evaluate the effect of depression on cardiac morbidity. By analyzing the association between depression and all-cause mortality only, the true influence of depression on cardiac-related events may have been underestimated. ${ }^{7}$ We found that, apart from decreased survival following CABG, pre-existing depression was significantly associated with an increase in our composite end point of major adverse cardiovascular events, including hospital readmission. These data provide a more complete analysis of the overall effect of pre-existing depression on long-term survival and cardiac-related events after surgical revascularization. Previous meta-analyses reported an increased risk of mortality in depressed patients with stable CAD or following myocardial infarction. Our analysis not only confirms these findings, but also demonstrates that the risk persists despite revascularization.

Moreover, given the variability in the definition of exposure between studies, subgroup analysis was undertaken here to determine whether the definition of depression altered the observed inverse relationship with all-cause mortality. Regardless of how depression was defined in our study, either by questionnaire or administrative records, the increase in mortality associated with depression persisted. However, the effect was $24 \%$ greater when questionnaires were used to define depression. Conversely, Stenman and colleagues, ${ }^{7}$ in their recent meta-analysis of a smaller cohort, found that no association between long-term survival and depression existed when depression was defined by questionnaires. Yet, when antidepressant use was used as a proxy for depression, these investigators observed a significant increase in mortality. Moreover, the variability in the modality used to define depression in our study may have influenced the magnitude of the association but not the direction, suggesting an increased risk of adverse outcomes in all patients with depression.

Our data confirm the findings of numerous individual reports that demonstrate a significant association between pre-existing depression and increased risk of developing neurovascular and cardiovascular comorbidities (eg, angina, myocardial infarction, and stroke), including readmission, particularly during long-term follow-up from CABG. Pathophysiologic explanations for the increased risk of adverse clinical outcomes attributable to psychological depression following CABG remains multifactorial. Historically, psychological depression is also strongly associated with an increased prevalence of traditional cardiovascular risk factors (eg, diabetes, dyslipidemia, systemic hypertension, smoking, sedentary lifestyles, and obesity), which suggests a potential bidirectional pathophysiologic mechanism linking the $2 .{ }^{13}$ In addition, novel mechanistic insight from recent studies suggests a causal relationship between psychological depression and autonomic and immune system dysregulation $^{32,33}$ instigating a proinflammatory systemic condition. ${ }^{34}$ When considered collectively with previous reports, our data reinforce that pre-existing psychological depression is not only a prognosticator for increased cardiac morbidity and mortality following CABG, but also may predict the development and progression of $\mathrm{CAD}$, which ostensibly is the most likely contributor to morbidity and long-term mortality in this cohort.

\section{Limitations}

There are several limitations to our analysis. First, the analysis is based on observational studies, leading to limitations due to the inherent design of the studies. Consequently, our results only suggest associations and cannot prove any causal association between depression and adverse outcomes after CABG. Second, studies may have been limited by confounding by both known confounders like concomitant valve surgery but also unknown confounders despite the adjustment made in the studies themselves. Third, a small number of female patients were included in the individual studies analyzed. That the effect of depression and heart disease is more complex in women means that any generalizations made here must be interpreted carefully in this context. ${ }^{35,36}$ Fourth, in a number of the studies analyzed, the diagnosis 
of depression was made before CABG with no follow-up assessment regarding temporal changes in diagnosis or severity of depression. Fifth, there was variability in the time to follow-up and assessment of morbidity and mortality that may have contributed to the heterogeneity encountered in our results. However, this heterogeneity will affect the magnitude of the association rather than the direction, which suggests an increased risk in all the studies. Sixth, we could not assess for publication bias because of the limited number of studies in our analysis. Finally, our underlying hypothesis was that pre-existing depression could have worse outcomes even in patients who undergo complete revascularization. An alternative inference would be that the magnitude of underlying coronary disease could affect both the severity of depressive symptoms and outcomes after surgery. However, the included studies adjusted for known covariates that may have affected the measured outcomes. As mentioned, to adjust both for known and unknown confounders will require individual patient level-data or can only be tested in a randomized controlled trial.

\section{Implications for Clinical Practice}

In addition to advancing our understanding of cardiac surgery and psychology, our results could potentially influence current clinical practices perhaps by placing a greater emphasis on the role of clinical psychologists/ psychiatrists in the preoperative assessment of patients undergoing cardiac surgery. This interdisciplinary approach could be realized in the form of more on-staff clinical psychologists in hospital settings and depression screening and postdischarge follow-up administered in a protocol-based manner. Implementing this paradigm would require more controlled studies to investigate the effect of the intervention on our measured outcomes.

\section{Implications for Research}

Data are lacking with regard to the relationship between depression severity and/or subtypes and the measured outcomes. The vast majority of the studies here were pooled together to include mild, moderate, and severe depression. Blumenthal and colleagues ${ }^{23}$ and others ${ }^{37}$ reported a higher risk of mortality depending on the severity of depression. Thus, whether depression severity influences clinical outcomes remains a matter of great debate.

\section{CONCLUSIONS}

Our analysis definitely demonstrates that pre-existing psychological depression is significantly associated with an increased risk for both all-cause mortality and major adverse cardiovascular events. These data are valuable for generating hypotheses and warrant future randomized trials to confirm our findings and to further investigate the effect of intervention on clinical outcomes in this particular cohort.

\section{Conflict of Interest Statement}

Authors have nothing to disclose with regard to commercial support.

The authors thank Michel Atlas for helping in the development of the search strategy and the literature search.

\section{References}

1. Kessler RC, Berglund P, Demler O, Jin R, Merikangas KR, Walters EE Lifetime prevalence and age-of-onset distributions of DSM-IV disorders in the National Comorbidity Survey Replication. Arch Gen Psychiatry. 2005;62: 593-602.

2. Celano CM, Huffman JC. Depression and cardiac disease: a review. Cardiol Rev. 2011;19:130-42.

3. Barth J, Schumacher M, Herrmann-Lingen C. Depression as a risk factor for mortality in patients with coronary heart disease: a meta-analysis. Psychosom Med. 2004;66:802-13.

4. Meijer A, Conradi HJ, Bos EH, Thombs BD, van Melle JP, de Jonge P. Prognostic association of depression following myocardial infarction with mortality and cardiovascular events: a meta-analysis of 25 years of research. Gen Hosp Psychiatry. 2011;33:203-16.

5. van Melle JP, de Jonge P, Spijkerman TA, Tijssen JG, Ormel J, van Veldhuisen DJ, et al. Prognostic association of depression following myocardial infarction with mortality and cardiovascular events: a meta-analysis. Psychosom Med. 2004;66:814-22.

6. Nicholson A, Kuper H, Hemingway H. Depression as an aetiologic and prognostic factor in coronary heart disease: a meta-analysis of 6362 events among 146538 participants in 54 observational studies. Eur Heart J. 2006;27:2763-74.

7. Stenman M, Holzmann MJ, Sartipy U. Association between preoperative depression and long-term survival following coronary artery bypass surgery-a systematic review and meta-analysis. Int J Cardiol. 2016;222:462-6.

8. Beresnevaite M, Benetis R, Taylor GJ, Jureniene K, Kinduris S, Barauskiene V. Depression predicts perioperative outcomes following coronary artery bypass graft surgery. Scand Cardiovasc J. 2010;44:289-94.

9. Burg MM, Benedetto MC, Soufer R. Depressive symptoms and mortality two years after coronary artery bypass graft surgery (CABG) in men. Psychosom Med. 2003;65:508-10.

10. Frasure-Smith N, Lesperance F. Depression and coronary artery disease. Herz 2006;31(Suppl 3):64-8.

11. Phillips-Bute B, Mathew JP, Blumenthal JA, Grocott HP, Laskowitz DT, Jones RH, et al. Association of neurocognitive function and quality of life 1 year after coronary artery bypass graft (CABG) surgery. Psychosom Med. 2006;68:369-75.

12. Stenman M, Holzmann MJ, Sartipy U. Antidepressant use before coronary artery bypass surgery is associated with long-term mortality. Int J Cardiol. 2013;167: 2958-62.

13. Tully PJ. Psychological depression and cardiac surgery: a comprehensive review. J Extra Corpor Technol. 2012;44:224-32.

14. Tully PJ, Winefield HR, Baker RA, Turnbull DA, de Jonge P. Confirmatory factor analysis of the Beck Depression Inventory-II and the association with cardiac morbidity and mortality after coronary revascularization. J Health Psychol. 2011;16:584-95.

15. Scherer RW, Langenberg P, von Elm E. Full publication of results initially presented in abstracts. Cochrane Database Syst Rev. 2007;MR000005.

16. Taddio A, Pain T, Fassos FF, Boon H, Ilersich AL, Einarson TR. Quality of nonstructured and structured abstracts of original research articles in the British Medical Journal, the Canadian Medical Association Journal and the Journal of the American Medical Association. Can Med Assoc J. 1994;150: $1611-5$.

17. Higgins JP, Thompson SG, Deeks JJ, Altman DG. Measuring inconsistency in meta-analyses. BMJ. 2003;327:557-60.

18. Wells G, Shea B, O'Connell D, J Peterson, V Welch, M Losos, et al. The Newcastle- Ottawa scale (NOS) for assessing the quality of nonrandomized studies in meta-analysis. Available at: http://www.ohri.ca/programs/clinical epidemiology/oxford.asp. Accessed January 25, 2015.

19. Liberati A, Altman DG, Tetzlaff J, Mulrow C, Gotzsche PC, Ioannidis JP, et al The PRISMA statement for reporting systematic reviews and meta-analyses of studies that evaluate healthcare interventions: explanation and elaboration. BMJ. 2009;339:b2700. 
20. Stroup DF, Berlin JA, Morton SC, Olkin I, Williamson GD, Rennie D, et al. Meta-analysis of observational studies in epidemiology: a proposal for reporting. Meta-analysis of Observational Studies in Epidemiology (MOOSE) group. JAMA. 2000;283:2008-12.

21. Connerney I, Shapiro PA, McLaughlin JS, Bagiella E, Sloan RP. Relation between depression after coronary artery bypass surgery and 12-month outcome: a prospective study. Lancet. 2001;358:1766-71.

22. Connerney I, Sloan RP, Shapiro PA, Bagiella E, Seckman C. Depression is associated with increased mortality 10 years after coronary artery bypass surgery. Psychosom Med. 2010;72:874-81.

23. Blumenthal JA, Lett HS, Babyak MA, White W, Smith PK, Mark DB, et al. Depression as a risk factor for mortality after coronary artery bypass surgery. Lancet. 2003;362:604-9.

24. Oxlad M, Stubberfield J, Stuklis R, Edwards J, Wade TD. Psychological risk factors for cardiac-related hospital readmission within 6 months of coronary artery bypass graft surgery. J Psychosom Res. 2006;61:775-81.

25. Xiong GL, Jiang W, Clare R, Shaw LK, Smith PK, Mahaffey KW, et al. Prognosis of patients taking selective serotonin reuptake inhibitors before coronary artery bypass grafting. Am J Cardiol. 2006;98:42-7.

26. Tully PJ, Baker RA, Knight JL. Anxiety and depression as risk factors for mortality after coronary artery bypass surgery. J Psychosom Res. 2008;64: 285-90.

27. Dao TK, Chu D, Springer J, Gopaldas RR, Menefee DS, Anderson T, et al. Clinical depression, posttraumatic stress disorder, and comorbid depression and posttraumatic stress disorder as risk factors for in-hospital mortality after coronary artery bypass grafting surgery. J Thorac Cardiovasc Surg. 2010;140: 606-10.

28. Tully PJ, Cardinal T, Bennetts JS, Baker RA. Selective serotonin reuptake inhibitors, venlafaxine and duloxetine are associated with in hospital morbidity but not bleeding or late mortality after coronary artery bypass graft surgery. Heart Lung Circ. 2012;21:206-14.

29. Stenman M, Holzmann MJ, Sartipy U. Relation of major depression to survival after coronary artery bypass grafting. Am J Cardiol. 2014;114: 698-703.

30. Stenman M, Holzmann MJ, Sartipy U. Do socioeconomic factors modify the association between preoperative antidepressant use and survival following coronary artery bypass surgery? Int J Cardiol. 2015;198:206-12.

31. Baker RA, Andrew MJ, Schrader G, Knight JL. Preoperative depression and mortality in coronary artery bypass surgery: preliminary findings. ANZ J Surg. 2001;71:139-42.

32. Otte C, Neylan TC, Pipkin SS, Browner WS, Whooley MA. Depressive symptoms and 24-hour urinary norepinephrine excretion levels in patients with coronary disease: findings from the Heart and Soul Study. Am J Psychiatry. 2005; 162:2139-45.

33. Licht CM, de Geus EJ, Zitman FG, Hoogendijk WJ, van Dyck R, Penninx BW. Association between major depressive disorder and heart rate variability in the Netherlands Study of Depression and Anxiety (NESDA). Arch Gen Psychiatry. 2008;65:1358-67.

34. Tawakol A, Ishai A, Takx RA, Figueroa AL, Ali A, Kaiser Y, et al. Relation between resting amygdalar activity and cardiovascular events: a longitudinal and cohort study. Lancet. 2017;389:834-45.

35. Moller-Leimkuhler AM. Women with coronary artery disease and depression: a neglected risk group. World J Biol Psychiatry. 2008;9:92-101.

36. Möller-Leimkühler AM. Gender differences in cardiovascular disease and comorbid depression. Dialogues Clin Neurosci. 2007;9:71-83.

37. White J, Zaninotto P, Walters K, Kivimaki M, Demakakos P, Shankar A, et al. Severity of depressive symptoms as a predictor of mortality: the English longitudinal study of ageing. Psychol Med. 2015;45:2771-9. 
TABLE E1. Covariate or confounders matched for propensity matching or adjusted for the multivariate analysis

\begin{tabular}{|c|c|}
\hline Source & Covariates \\
\hline $\begin{array}{l}\text { Connerney, } \\
2001 \text { and } 2010\end{array}$ & Female gender, living alone, LVEF $<0.35$, hospital stay $>5 \mathrm{~d}$, NYHA, complexity of surgical procedure \\
\hline Blumenthal, 2003 & Age, LVEF, number of grafts, sex, history of myocardial infarction, history of smoking, and diabetes \\
\hline Olad, 2006 & Cardiopulmonary bypass time \\
\hline Xiong, 2006 & $\begin{array}{l}\text { Covariates in propensity modeling were age, race, gender, smoking, family history of coronary artery disease, DM, HTN, HPL, } \\
\text { chronic lung disease, immunosuppressive therapy, PVD, CVD, previous cardiovascular intervention, previous MI, CHF, } \\
\text { angina, cardiogenic shock, NYHA, previous CABG, previous PCI, and the use of aspirin, beta blockers, angiotensin-converting } \\
\text { enzyme inhibitors, intravenous nitrates, and anticoagulants }\end{array}$ \\
\hline Tully, 2008 & $\begin{array}{l}\text { Age (quartiles), female sex, LVEF, urgency of surgery (elective vs urgent), chronic lung disease, CHF, DM, PVD, renal disease, } \\
\text { previous MI within } 90 \mathrm{~d}, \mathrm{HTN}, \mathrm{CCS} \text { class, and psychoactive medication use (ie, antidepressants, sedatives, anxiolytics, and } \\
\text { antihypnotics) }\end{array}$ \\
\hline Dao, 2010 & $\begin{array}{l}\text { Age, gender, race, median household income } \\
\text { Deyo Cherkin \& Ciol comorbidity index, which includes MI, CHF, PVD, CVD, DM, dementia, rheumatologic disease, peptic } \\
\text { ulcer disease, mild liver disease, diabetes, diabetes with chronic complications, hemiplegia or paraplegia, renal disease, } \\
\text { malignancy, moderate or severe liver disease, metastatic solid tumor, and AIDS/HIV }\end{array}$ \\
\hline Tully, 2011 & LVEF, age, respiratory disease, heart failure, renal disease and diabetes \\
\hline Tully, 2012 & $\begin{array}{l}\text { Propensity variables were age, female sex, urgency of surgery (emergency/salvage, urgent, or elective), previous MI, LVEF, } \\
\text { respiratory disease, renal disease, peripheral, DM, HTN, PVD, CVD, CHF, cardiogenic shock, smoking, and OPCAB } \\
\text { procedure }\end{array}$ \\
\hline Stenman, 2014 & $\begin{array}{l}\text { Age, gender, estimated glomerular filtration rate, preoperative left ventricular function, diabetes mellitus, chronic obstructive } \\
\text { pulmonary disease, peripheral vascular disease, acute kidney injury, previous stroke, and previous heart failure }\end{array}$ \\
\hline Stenman, 2015 & $\begin{array}{l}\text { Age, gender, region, body mass index, DM, HTN, HPL, PVD, COPD, prior MI, prior PCI, heart failure, stroke, atrial fibrillation, } \\
\text { LVEF, alcohol dependency, cancer, education, civil status, and family disposable income }\end{array}$ \\
\hline
\end{tabular}

